\title{
A case of labioscrotal ovotestis in Madagascar with review of the literature
}

\begin{abstract}
Among the disorder sexual development which regroups several pathological entities, true hermaphroditism or Ovotestis disorder remains a rare variety. We report a case of true hermaphroditism, diagnosed at the age of 15 years. Despite the presence of sexual ambiguity at birth, the female gender has been declared. The presence of a female genital tract and secondary sexual characteristics has led the choice of scrotal excision. The surgical procedure, the histological study bestow the positive diagnosis and allowed to revise the sexual ambiguity.
\end{abstract}

Volume II Issue 5 - 2020

\author{
Ranaivoson Haingo Voahangy Rabetafika,' \\ Zo Irène Raivoherivony,' Aristide \\ Romain Raherison, ${ }^{2}$ Mamy Lalatiana \\ Andriamanarivo, ${ }^{2}$ Nantenaina Soa \\ Randrianjafisamindrakotroka' \\ 'Pathology Department, Center Hospital University Joseph \\ Ravoahangy Andrianavalona, Antananarivo Madagascar \\ ${ }^{2}$ Pediatric Surgery, Center Hospital University Joseph \\ Ravoahangy Andrianavalona, Antananarivo Madagascar
}

Correspondence: Ranaivoson Haingo Voahangy Rabetafika Pathology Department Center Hospital University- Joseph Ravoahangy Andrianavalona, III 051 bis Ouest Mananjara Antananarivo, Madagascar, Tel +261347045040, Email mahango@yahoo.fr

Received: July 30, 2020 | Published: September II, 2020

\section{Introduction}

True hermaphroditism is a very rare pathology whose incidence is about $1 / 100000$ births. $^{1}$ Quite recently, a nomenclature consensus for disorders or defects of sexual development (DSD) has been proposed. In this classification, true hermaphroditism is referred to as ovotestis-DSD. ${ }^{2}$ It was defined by the coexistence in the same individual of bisexual gonads, testicular tissue with distinct tubules and ovarian tissue, containing follicles or corpora albicantia. ${ }^{3}$ These two components secrete male and female hormones, responsible for sexual ambiguity. Delayed diagnosis of true hermaphroditism can have a severe psychological impact on the patient, hence the value of early diagnosis and good management. ${ }^{4}$ Our study reports a case of true hermaphroditism or ovotestis-DSD discovered at the age of 15 years. The aims of this study are to describe the importance of pathology for confirming the diagnosis and to show the primary interest of surgery in management.

\section{Patient and observation}

It was an individual who has 15-year-old, declared a female gender at birth. On physical examination, female-type secondary sexual characteristics were normal, including well-developed mammary glands, triangular pubic hairiness, and a regular endometrial cycle since one year before the diagnosis. The external genital tracts, showed sexual ambiguity (Figure 1) with a normal hymen, a vaginal vestibule, small and large hypotrophy lips, and a hypertrophy clitoris taking the appearance of a penis measuring $2.5 \mathrm{~cm}$. The labioscrotal (para-clitoral) region contained a scrotum within which an ovoid, mobile mass, the size of a normal testicle, was palpated. For the internal genital tracts, pelvic ultrasound showed a deviated uterus on the left and a left ovary, both normal. Surgery was decided and consisted of excision of the intrascotal mass, followed by vaginoplasty and enlargement associated with a clitoral reduction plasty (Figure 2). Macroscopically, the mass looked like a normal testicle capped by the epididymis (Figure 3). On histological examination (Figure 4), coexistence of ovarian parenchyma with ovarian follicles at different stages of maturation, and testicular with seminiferous tubules associated with hyperplastic Leydig cells were observed. Both parenchymas are separated by a connective thin stroma. Epididymal and vas deferens ducts were normal (Figure 5). Following treatment consisted of a vaginal calibration with candles every week after the healing of the surgical wound. The patient was lost sight of after 3 calibration sessions.

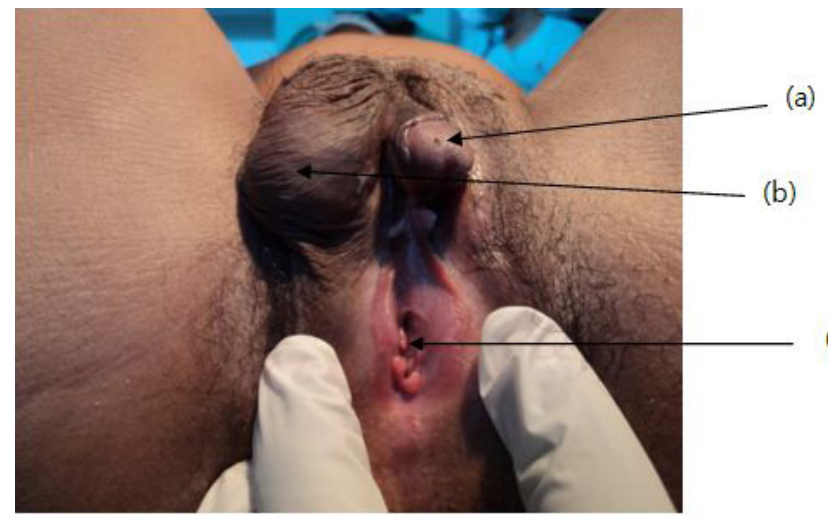

Figure I External genitalia.

a) Hypertrophy clitoris

b) Scrotum

c) Vaginal vestibule. 


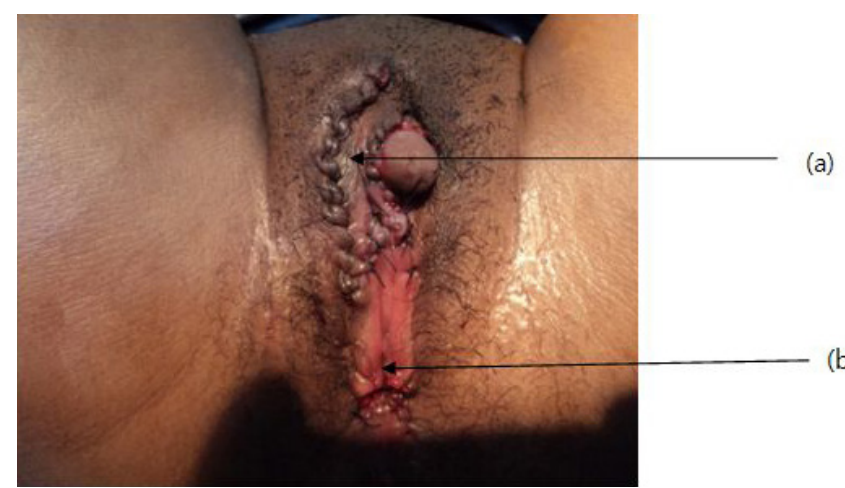

Figure 2 External genitalia after surgery.

a) Clitoridoplasty

b) Vaginoplasty.

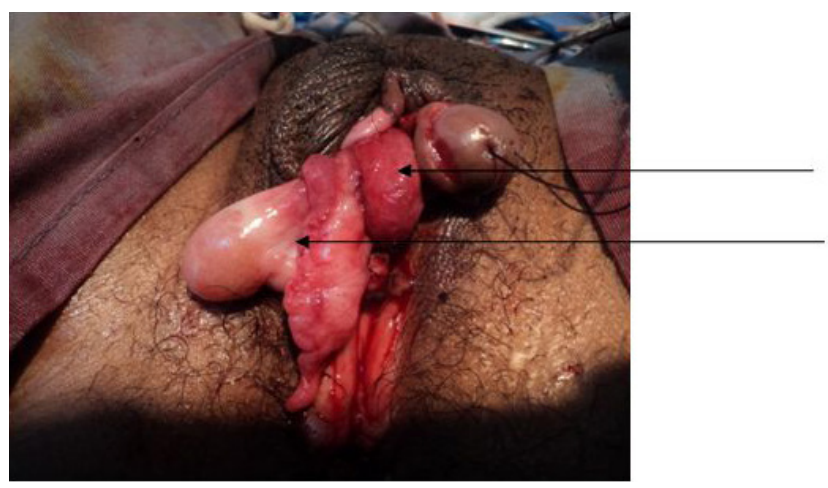

Figure 3 Macroscopy appearance.

a) Female gonad

b) Male gonad.

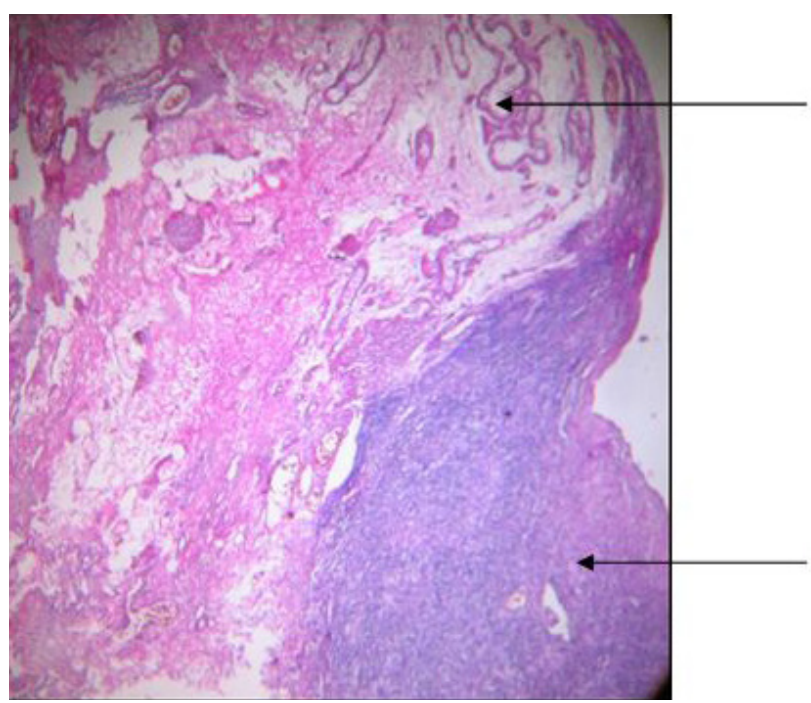

Figure 4 Ovary and testicular parenchyma. 100x.

a) Seminiferous tubes

b) Ovary parenchyma.

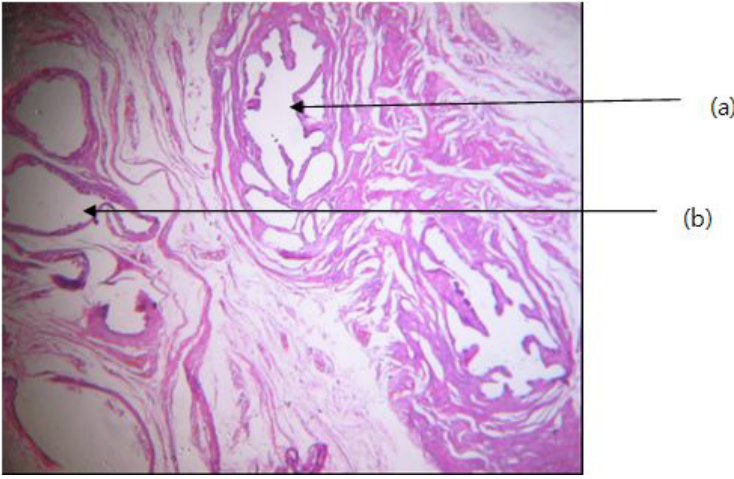

Figure 5 Epididymal and deferent duct. 200x.

a) Deferent duct

b) Epididymal duct.

\section{Discussion}

Depending on the location and histology of the gonads, M.Z Iqbal ${ }^{5}$ and al classify the ovotestis-DSD into 3 varieties: bilateral, ovotestisDSD bilateral; 2, unilateral, an ovotestis on one side and an ovary or testicle on the contralateral side; side, an ovary on one side and a testicle on the other. At the sight of the structures present in our case, our ovotestis-DSD is classified unilaterally with a DSD ovotestis in para-clitoral labioscrotal localization on the right side associated with an ovary in normal position on the left side. B.P. Kropp and al reported that ovotestis-DSD is most commonly found on the right side of an ovarian site. ${ }^{6}$ Our case is a rather rare variety: firstly, it is unilateral and this represents only $20 \%$ of cases according to M. Z Iqbal and al. ${ }^{5}$ Secondly, it is in labioscrotal localization, a rare site for ovotestis-DSD because it represents only $25 \%$ of cases according to H. Barseghyan and al. ${ }^{7}$ Ovotestis-DSD may be at any level along the path of embryonic testicular migration. Therefore the amount of testicular tissue present in the ovotestis-DSD determinated the migration and position of the gonads. ${ }^{7}$

Depending on the morphological feature of the internal genitals, the degree of virilization depends on the ability of the testes to secrete testosterone and the presence or absence of a uterus and fallopian tubes. ${ }^{8}$ But it is rare that the uterus is absent and according to Van Niekerk in $90 \%$ of the cases, a uterus is present but its development can be rudimentary. ${ }^{9}$ In our case the uterus and the left trunk were present.

For sex determination, approximately $70 \%$ of true hermaphrodites are reported as male, but less than $10 \%$ have a normal testis. ${ }^{10}$ In our case, the nurse declared it, at birth, of feminine gender despite the presence of a hypertrophied clitoris and a pseudo-testis. This is not really a mistake because later, the patient has realized abdomino-

(b) pelvic ultrasound and showed the presence of a uterus. According to $\mathrm{R}$ Raspa ${ }^{11}$ education as a woman is only recommended if the length of the stretched phallus is less than $2 \mathrm{~cm}$ or the presence of a vagina in a term newborn. In our case, despite a length of penis greater than $2 \mathrm{~cm}$, a treatment oriented in the female sense was chosen before the existence of normal female genital tract. In the literature, cases of true hermaphroditisms declared to be female are less frequent, as in the series of 13 cases of J.L. Simpson. ${ }^{2}$ Three out of seven individuals with 
uterus had their menstruation and were declared female. ${ }^{2}$ Similarly in the series of 125 patients of R. Wiersma, ${ }^{12} 9$ showed normal femaletype secondary sexual characteristics with a distinct urethral meatus and vaginal vestibule, three had a clitoris and the rest a penis-like structure, but only two have been declared as female. The presence of a uterus is not enough in itself to characterize the gender of an individual. The combination of several criteria, including aspects of the external and internal genital tracts, the presence of normal secondary sexual characteristics, the morphological characteristics of the ovary and testicular parenchyma, and the result of the karyotype guides the choice of the individual's gender. The same characteristics as those declared of the feminine gender of R Wiersma ${ }^{12}$ and J.L. Simpson ${ }^{2}$ were found in our case. Our patient had her first menstruation when she was 14 years old. Secondary sexual characteristics are present and normal, such as the absence of a beard, the presence of pubic hair of the triangular type, well-developed mammary glands.

Depending on the phenotype, specific morphological characteristics for each type of phenotype were developed by J.L. Simpson. ${ }^{13}$ The testicular and ovarian parenchyma observed in our case, including the presence of ovarian follicles at different stages of maturation, are typical of an ovotestis-DSD with a 46, XX phenotype according to J.L. Simpson criteria. ${ }^{13}$ The karyotype study was proposed in our case but the patient could not perform it. Regarding the treatment, a vaginoplasty associated with a clitoridoplasty was decided in order to correct the sexual ambiguity.

\section{Conclusion}

True hermaphroditism or ovotestis-DSD is a rare pathology of all DSD. Whatever the age of diagnosis, a histological study must be carried out for its diagnosis and classification. The choice of sex depends on the existing secondary sexual characteristics and the anatomical state of the genital tract.

\section{Acknowledgments}

None.

\section{Author's contributions}

Each of the authors has read and concurs with the content of the final manuscript.

\section{Funding}

None.

\section{Conflicts of interest}

The authors declare that they have no conflicts of interest.

\section{References}

1. Hadjidekov G, Kirova G, Minkov M, et al. L'apport de l'imagerie dans le bilan diagnostic chez un nourrisson de 3 mois avec hermaphrodisme vrai. Journal de Radiologie. 2007;88(1):80-83.

2. Lee PA, Houk CP, Ahmed SF, et al. Consensus statement on management of intersex disorders. International consensus conference on intersex. Pediatrics. 2006;118(2):488-500.

3. Diamond DA. Sexual differentiation: normal and abnormal. In: Walsh PC, Retik AB, Vaughan ED, editors. Saunders, New York: Campbell's urology; 2004.

4. Hughes W, Erickson CC, Fleischmann W, et al. True hermaphroditism. The Journal of Pediatrics. 1958;52(6):662-669.

5. Iqbal MZ, Jam MR, Saleem M, et al. True hermaphrodite: a case report. APSP Journal of Case Reports. 2011.

6. Kropp BP, Keating MA, Moshang T, et al. True hermaphroditism and normal male genitalia: an unusual presentation. Urology. 1995;46(5):736739.

7. Barseghyan H, Vilain E. The genetics of ovotesticular disorders of sex development. In: New MI, Parsa A, Yuen TT, editors. Genetic Steroid Disorders, New Yorkl: Elsevier; 2013:261-263.

8. Kadir C, Ekrema A, Mustafa G, et al. True hermaphrodism presenting as an inguinal hernia. International Braz J Urol. 2007;33(1):72-73.

9. Van Niekerk WA. True Hermaphroditism. American Journal of Obstetrics Gynecology. 1976;126(7):890-907.

10. Conte FA, Grumbach MM. Abnormalities of sexual determination and differentiation. In: Tanagho EA, McAninch JW, editors. New York: Smith's General Urology International Edition; 2000:699-736.

11. Raspa RW, Subramaniam AP, Romas NA. True hermaphroditism presenting as intermittent hematuria and groin pain. Urology. 1986;28(2):133-136.

12. Wiersma R. The clinical spectrum and treatment of ovotesticular disorder of sexual development. Adv Exp Med Biol. 2011;707:101-103.

13. Simpson JL. True hermaphroditism. Glob libr Women's med. 2011. 